\title{
PERANCANGAN VIDEO ANIMASI 2D "METAMORFOSIS KATAK" MENGGUNAKAN TEKNIK MOTION GRAPHIC SEBAGAI MEDIA PEMBELAJARAN
}

\author{
Moch Farid Fauzi ${ }^{1)}$, Titaj Setio Wibowo ${ }^{2)}$ \\ 1) Sistem Informasi Universitas AMIKOM Yogyakarta \\ ${ }^{2)}$ Informatika Universitas AMIKOM Yogyakarta \\ email : faridfauzi@amikom.ac.id ${ }^{1)}$, titaj.1770@students.amikom.ac.id ${ }^{2)}$
}

\begin{abstract}
Abstraksi
Banyak pelajaran yang bisa dicontohkan langsung oleh alam dalam mata pelajaran Ilmu Pengetahuan Alam. Salah satunya berkaitan dengan makhluk hidup, seperti sebuah proses metamorfosis pada katak. Metamorfosis katak merupakan metamorfosis sempurna karena bentuk tubuhnya yang berbeda pada setiap fase metamorfosisnya. Proses pembelajaran metamorfosis katak akan lebih mudah dipahami oleh siswa jika disajikan dalam sebuah penjelasan dan contoh yang detail. Lembaga riset dan penelitian komputer, Computer Technology Research (CTR), menyatakan bahwa orang lebih mampu mengingat $80 \%$ dari yang dilihat, didengar dan dilakukan sekaligus. Penulis bermaksud membuat video animasi 2D pada proses metamorfosis katak guna menunjang proses pembelajaran pada siswa agar dapat lebih mudah dalam menangkap pembelajaran karena disajikan dalam bentuk animasi dan juga dilengkapi dengan informasi yang detail. Animasi ini dibangun dengan menggunakan Adobe After Effect 2020 sebagai salah satu aplikasi utama dalam proses penganimasian dengan teknik motion graphic.
\end{abstract}

Kata Kunci :

metamorfosis katak, animasi, motion graphic, multimedia, pembelajaran

\begin{abstract}
Many lessons can be exemplified directly by nature in the Natural Sciences subjects. One of them relates to living things, such as metamorphosis in frogs. The frog's metamorphosis is complete because its body shape is different at each stage of its metamorphosis. The learning process of frog metamorphosis will be more straightforward for students to understand if presented in a detailed explanation and example. Computer research and research institute, Computer Technology Research, states that people can better remember $80 \%$ of what they see, hear and do all at once. The author intends to make a $2 D$ animated video on the frog's metamorphosis process to support the learning process for students so that it can be easier to capture learning because it is presented in animated form and is also equipped with detailed information. This animation was built using Adobe After Effects 2020 as one of the leading applications in the animation process with motion graphic techniques.
\end{abstract}

\section{Keywords :}

frog metamorphosis, animation, motion graphics, multimedia, learning

\section{Pendahuluan}

Metamorfosis dapat didefinisikan sebagai suatu perubahan individu pada makhluk hidup dari telur sampai menjadi dewasa yang sempurna dengan mengalami perubahan bentuk morfologi, anatomi bahkan fisiologis. Metamorfosis sempurna merupakan metamorfosis perkembangan individu makhluk hidup melalui tahap dari telur-larva-pupadewasa [1].

Pada mata pelajaran Ilmu Pengetahuan Alam (IPA) terdapat banyak pembelajaran yang bisa dicontohkan langsung oleh alam, dan salah satunya berkaitan dengan makhluk hidup, seperti proses metamorfosis yang terjadi pada katak. Metamorfosis pada katak termasuk jenis metamorfosis sempurna, karena bentuk tubuh katak sangat berbeda pada setiap fase metamorfosisnya.

Proses pembelajaran metamorfosis pada katak membutuhkan penjelasan serta contoh secara detail agar siswa lebih mudah dalam memahami proses metamorfosis yang terjadi. Dalam membantu proses pembelajaran menjadi lebih menarik penulis bermaksud untuk membuat video animasi 2D tentang proses metamorfosis yang terjadi pada katak. Hal ini bertujuan agar siswa dapat lebih mudah dalam menangkap pembelajaran karena disajikan dalam animasi 2D yang lebih menarik dan dilengkapi dengan informasi secara detail.

Lembaga riset dan penelitian komputer, yaitu Computer Technology Research (CTR), menyatakan bahwa setiap orang dapat mengingat $20 \%$ dari yang 
dilihatnya dan $30 \%$ dari yang didengarnya, serta $50 \%$ dari yang dilihat dan didengarnya. Tetapi setiap orang akan mampu mengingat $80 \%$ dari yang dilihat, didengar dan dilakukannya sekaligus. Dalam hal ini melalui peran multimedia animasi dapat mencakup penglihatan, pendengaran dan sekaligus melakukan sebuah pembelajaran [2].

Melalui peran teknologi animasi diharapkan pembelajaran pada proses metamorfosis katak dapat lebih menarik, modern dan informasi yang diberikan lebih mudah dipahami dalam proses pembelajaran. Animasi ini dibangun dengan menggunakan Adobe After Effect 2020 sebagai salah satu aplikasi utama dalam proses penganimasian dengan teknik motion graphic.

Motion graphic merupakan media yang mengkombinasikan antara teks dan gambar yang bergerak pada suatu ruang dan waktu. Motion graphic sering digunakan pada siaran televisi atau film untuk membantu penyampaian pesan yang terkandung dalam cerita. Teknik penggabungan gambar dan suara pada motion graphic dapat meningkatkan kepuasan dalam menentukan ide, sehingga dapat mempengaruhi emosi dari penonton [3].

Penelitian disusun menggunakan metode pra produksi, produksi, dan pasca produksi. Pengambilan data dilakukan dengan menggunakan literasi dari buku pelajaran IPA untuk Sekolah Dasar. Data yang didapat kemudian diolah menjadi video animasi 2D metamorfosis katak. Video ini akan di publikasikan di kanal Youtube.

Penelitian ini merujuk pada penelitian yang pernah dilakukan sebelumnya. Sidik pada [4] melakukan penelitian yang bertujuan memberikan informasi pengisian data diri calon mahasiswa baru Universitas Negeri Jakarta saat penerimaan mahasiswa baru. Video informasi yang dibuat menggunakan teknik motion graphic.

Puspitasari pada [5] melakukan penelitian yang bertujuan mengedukasi siswa SD melalui media interaktif dalam mempelajari nama anak binatang menggunakan Bahasa Jawa

Fujianto dan Antoni pada [6] melakukan penelitian untuk mengetahui tingkat efektivitas penggunaan video motion graphic sebagai media promosi pada Zetizen Batam Pos.

\section{Metode Penelitian}

Penelitian ini disusun menggunakan metode pra produksi, produksi, dan pasca produksi. Tahap Pra poduksi adalah tahap penyusunan tema, konsep, dan persiapan perangkat lunak yang akan digunakan, serta naskah dan storyboard dari video animasi 2D yang akan dibuat. Tahap produksi adalah tahap pembuatan dari video animasi 2D dengan melakukan compositing, editing, dan rendering. Tahap pasca produksi adalah tahap akhir dengan melakukan pengujian dan implementasi. Langkahlangkah tersebut disajikan pada Gambar 1.

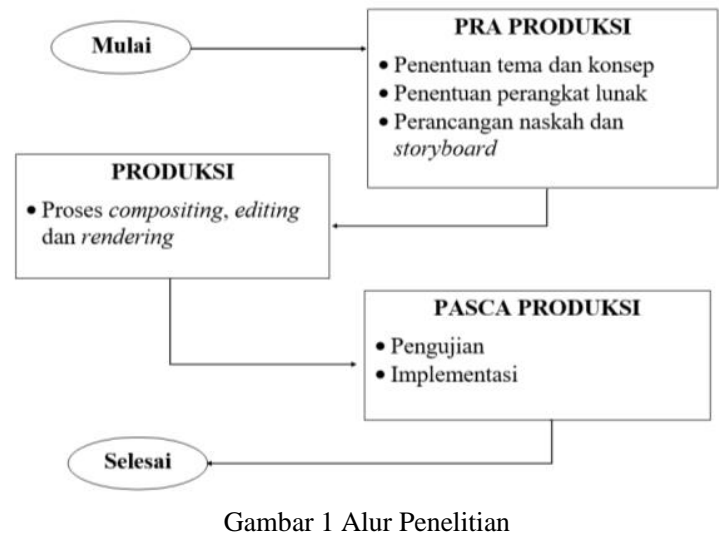

\section{Hasil dan Pembahasan}

\subsection{Analisis Kelayakan}

Analisis Kelayakan digunakan untuk menentukan apakah penelitian ini layak dilanjutkan atau diberhentikan.

\subsubsection{Analisis Kelayakan Teknologi}

Teknologi yang digunakan adalah teknologi yang biasa digunakan dalam produksi multimedia. Teknologi software yang digunakan antara lain Adobe Illustrator 2020 untuk membuat karakter, aset, dan latar tempat animasi, Adobe Premiere Pro 2020 untuk mengolah video, Adobe After Effect 2020 untuk pembuatan motion graphic dan penambah efek dalam video, Adobe Audition CC 2020 untuk mengolah audio, dan Adobe Photoshop CC 2020 untuk mengedit gambar. Berdasarkan analisis teknologi di atas, maka video yang akan dibuat telah memenuhi kelayakan teknologi.

\subsubsection{Analisis Kelayakan Operasional}

Analisis Kelayakan Operasional dapat tercapai jika informasi yang diberikan dapat menyelesaikan suatu permasalahan. Sesuai dengan permasalahan yang telah dijabarkan, video animasi video animasi 2D tentang proses metamorfosis katak ini harus dapat memberikan informasi seperti berikut:

1. Informasi tentang katak

2. Informasi metamorfosis pada katak

3. Tahapan dalam metamorfosis pada katak

Seluruh rangkaian informasi ini disajikan dengan wujud visual animasi 2D dan ditunjang menggunakan sebuah narasi.

\subsubsection{Analisis Kelayakan Hukum}

Berdasarkan hukum yang berlaku, sistem multimedia tidak diperbolehkan melanggar etika dan hukum yang diterapkan. Proyek pembuatan video ini bersifat mendidik dan tidak mengandung unsur SARA (Suku, Agama, Ras, dan Antar Golongan), tidak ada adegan kekerasan dan tidak menampilkan adegan pornografi ditinjau dari segi hukum dan peraturan hukum yang berlaku. 


\subsection{Analisis Kebutuhan Sistem}

\subsubsection{Analisis Kebutuhan Fungsional}

Kebutuhan fungsional merupakan kebutuhan yang berisi proses dan layanan apa saja yang nantinya harus disediakan sistem.

Melihat masalah yang dijelaskan di atas, maka kebutuhan fungsional sebuah video pengenalan Metamorfosis Katak antara lain:

1. Video pengenalan ini berformat Mp4 dengan teknik Motion Graphics.

2. Resolusi untuk video ini HD 1280x720 pixel.

3. Memuat informasi dalam bentuk teks, gambar, dan visual.

4. Memberikan informasi tentang Metamorfosis Katak.

\subsubsection{Analisis Kebutuhan Non Fungsional}

Kebutuhan Non Fungsional yang dibutuhkan dalam membangun Video Animasi 2D Metamorfosis Katak adalah kebutuhan perangkat keras (hardware) dan kebutuhan perangkat lunak (software).

Kebutuhan perangkat keras (hardware) yang dibutuhkan dalam membangun animasi 2D ditampilkan pada tabel 1 .

Tabel 1 Kebutuhan perangkat keras (hardware)

\begin{tabular}{cll}
\hline No & \multicolumn{1}{c}{ Jenis } & \multicolumn{1}{c}{ Spesifikasi } \\
\hline 1 & Motherboard & Mainboard R7-3750H GTX1650 \\
2 & Processor & AMD Ryzen $53750 \mathrm{H} 3.7 \mathrm{GHz}$ \\
3 & RAM & $12 \mathrm{~GB}$ \\
4 & Graphic Card & NVIDIA GeForce GTX 1650 \\
5 & Memory Size & $4018 \mathrm{MB}$ \\
6 & Memory Type & GDDR5 \\
\hline
\end{tabular}

Kebutuhan perangkat lunak (software) yang dibutuhkan dalam membangun animasi 2D ditampilkan pada tabel 2 .

Tabel 2 Kebutuhan perangkat lunak (software)

\begin{tabular}{cll}
\hline No & \multicolumn{1}{c}{ Fungsi } & \multicolumn{1}{c}{ Software } \\
\hline 1 & Mengolah gambar & $\begin{array}{l}\text { Adobe Photoshop CC 2020, Adobe } \\
\text { Illustrator 2021 }\end{array}$ \\
2 & Mengolah video & $\begin{array}{l}\text { Adobe After Effect CC 2020 } \\
\text { Adobe Audition CC 2020 }\end{array}$ \\
3 & Mengolah suara & Adobe Premiere Pro CC 2020 \\
4 & Rendering dan & \\
& finishing & Windows 10 (64 bit) \\
5 & Sistem Operasi &
\end{tabular}

\subsection{Tahap Pra Produksi}

Tahap pra produksi merupakan tahap awal dalam proses pembuatan video. Tahap pra produksi merupakan perancangan yang dilakukan untuk mempersiapkan segala sesuatu yang dibutuhkan di tahap produksi, yaitu mulai dari memilih tema, membuat konsep, pembuatan narasi dan storyboard.

\subsubsection{Tema}

Tema yang diusung dalam video Metamorfosis Katak ini berhubungan dengan ilmu sains pada suatu mata pelajaran Ilmu Pengetahuan Alam. Video animasi 2D ini dapat memvisualkan materi dan menunjang proses pembelajaran pada siswa dalam menangkap pembelajaran karena disajikan dalam bentuk animasi dan juga dilengkapi dengan informasi yang detail.

\subsubsection{Konsep}

Konsep video pengenalan ini menyajikan penyampaian informasi yang mengandung teks, gambar dan audio. Informasi yang disajikan dibuat sesingkat dan padat mungkin agar mudah dipahami, kemudian dipadukan dengan kombinasi warna dengan kontras yang seimbang.

\subsubsection{Naskah}

Naskah merupakan urutan teks atau dialog yang akan dibacakan oleh narator bersama dengan pergerakan video yang akan dibuat. Video animasi ini narasi dibuat seringkas mungkin akan tetapi jelas agar mudah dipahami oleh peserta didik.

\begin{tabular}{|c|c|}
\hline \multicolumn{2}{|l|}{ Tabel 3 Naskah } \\
\hline Naskah & Scene \\
\hline $\begin{array}{l}\text { Halo teman, siapa sih yang tidak tahu katak? } \\
\text { Katak merupakan hewan amfibi atau hewan yang } \\
\text { dapat hidup di dua alam yaitu di air dan di } \\
\text { daratan. Katak memiliki banyak jenis, tak jarang } \\
\text { keberagaman jenis katak membuat orang tertarik } \\
\text { untuk memeliharanya. Tapi tahukah kalian kalau } \\
\text { katak berasal dari hewan yang tidak disukai? } \\
\text { Yaitu kecebong. Perubahan bentuk ini disebut } \\
\text { Metamorfosis. }\end{array}$ & $\begin{array}{l}\text { scene } 1, \\
\text { scene } 2\end{array}$ \\
\hline $\begin{array}{l}\text { Nah, metamorfosis adalah proses perubahan fisik } \\
\text { pada hewan. Hasil dari metamorfosis dapat } \\
\text { mengubah seluruh organ tubuh. Lalu, bagaimana } \\
\text { bisa proses yang terjadi dari kecebong hingga } \\
\text { menjadi katak? Hal itu membuat metamorfosis } \\
\text { dinilai sebagai transformasi yang luar biasa. } \\
\text { Katak adalah hewan yang mengalami } \\
\text { metamorfosis sempurna. karena sejak menetas } \\
\text { dari telur hingga dewasa, katak mengalami } \\
\text { perubahan bentuk fisik yang sangat berbeda. }\end{array}$ & $\begin{array}{l}\text { scene } 3, \\
\text { scene 4, } \\
\text { scene } 5, \\
\text { scene } 6\end{array}$ \\
\hline $\begin{array}{l}\text { Berikut tahapan metamorfosis katak. } \\
\text { Pertama, Seekor katak hidup dari telur. Bentuk } \\
\text { telur katak seperti biji selasih, atau biji markisa. } \\
\text { Telur katak biasanya terletak di daunan atau } \\
\text { bebatuan. [7] }\end{array}$ & scene 7 \\
\hline
\end{tabular}

Tabel 3 Lanjutan

\begin{tabular}{lc} 
Tabel 3 Lanjutan & Scene \\
\hline Nkhirnya telur menetas dan berubah menjadi & scene 8, \\
larva. Tahap ini biasa disebut dengan kecebong & scene 9 \\
atau berudu. Kecebong bernapas menggunakan & \\
insang. Yang hanya bisa kecebong lakukan & \\
adalah memakan tumbuhan yang ada di rawa, \\
baik yang masih segar atau bagian sisa \\
tumbuhan. Ketika kecebong terus makan maka ia \\
akan tumbuh dan berkembang. Proses \\
pertumbuhan kecebong terjadi selama kurang \\
lebih 5 minggu. Pertumbuhannya ditandai \\
dengan tumbuhnya kaki, ekor, dan bentuk tubuh \\
yang membesar. \\
Di minggu ke 5, kecebong sudah berganti wujud & scene \\
menjadi katak muda. Katak muda memiliki ekor. & 10, \\
Ekor dari katak muda ini berfungsi untuk & scene 11 \\
menyimpan nutrisi, sehingga ia tidak perlu & \\
memakan apapun sampai benar-benar ekornya & \\
hilang. Perubahan yang terjadi pada katak muda &
\end{tabular}


adalah insang nya mulai menghilang, ekor mulai memendek, mulut mulai melebar dan paru-paru yang terbentuk mulai berfungsi. Ketika paru-paru sudah mulai berfungsi, katak muda sudah dapat beraktivitas di daratan. Fase ini hanya berlangsung sekitar 3 minggu sebelum menjadi katak dewasa.

Selanjutnya Katak dewasa. pada minggu ke 12, Katak dewasa sudah tidak memiliki insang yang sudah berganti menjadi paru-paru. Katak dewasa akan memakan serangga yang ditemukannya di daratan. Dalam fase ini katak dewasa sudah siap untuk berkembang biak. Dan katak sudah melewati tahap yang disebut metamorfosis sempurna.

Siklus metamorfosis ini akan terus berlanjut, Ketika katak bertemu dengan lawan jenis lalu bereproduksi. Lalu siklus katak akan mulai dari awal

\subsubsection{Storyboard}

Tahap berikutnya dalah perancangan storyboard untuk menggambarkan deskripsi tiap scene. Terdapat 14 scene yang dirancang sebagai acuan dalam menvisualkan video yang akan dibangun.

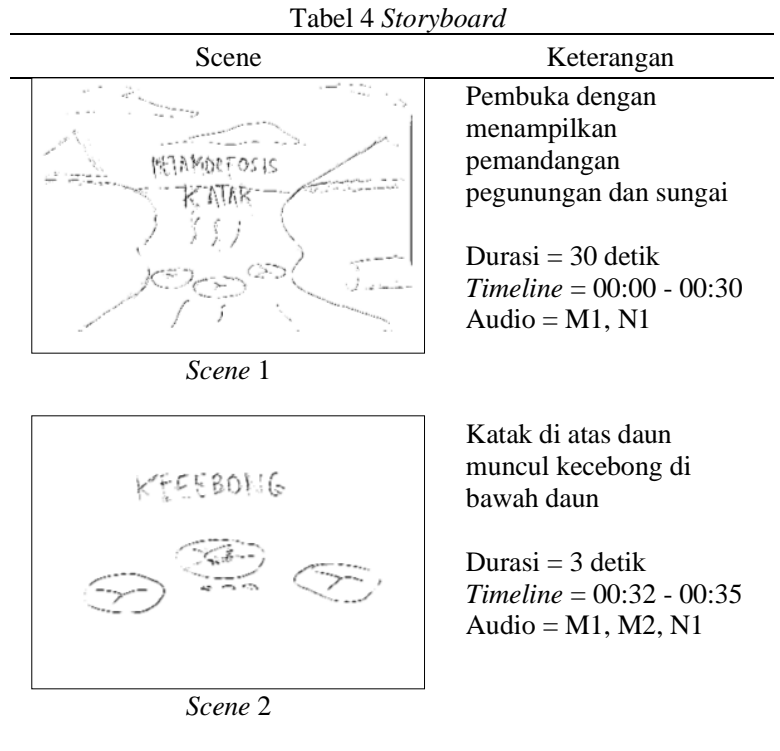

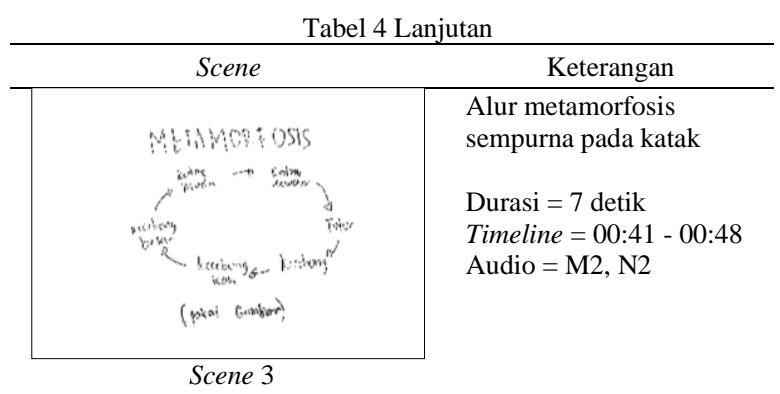

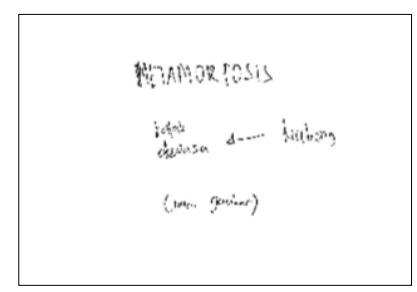

Scene 4

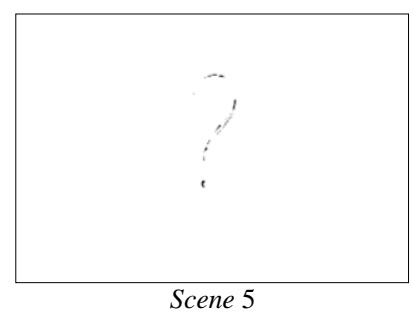

Scene 5

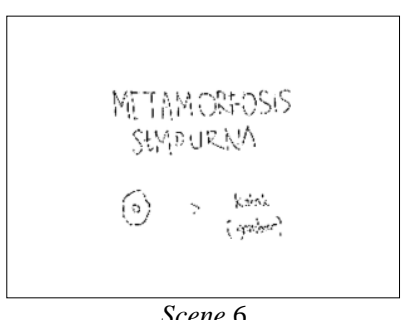

Scene 6

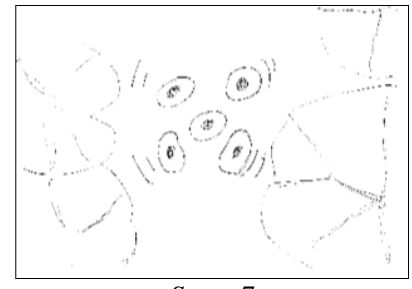

Scene 7

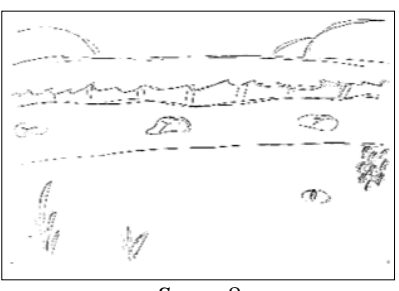

Scene 8

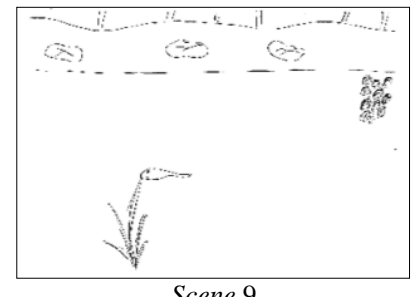

Scene 9
Menjelaskan tentang proses metamorfosis pada katak

Durasi $=3$ detik

Timeline $=00: 49-00: 52$

Audio $=\mathrm{M} 2, \mathrm{~N} 2$

Timbul sebuah pertanyaan

Durasi $=3$ detik

Timeline $=00: 53-00: 56$

Audio $=\mathrm{M} 2, \mathrm{~N} 2$

Penjelasan tentang metamorfosis sempurna pada katak

Durasi $=6$ detik

Timeline $=$ 00:57 - 01:03

Audio: M2, N2

Menampilkan fase telur diantara daun-daun dilihat dari sisi atas sungai

Durasi $=11$ detik Timeline $=01: 16-01: 35$ Audio $=\mathrm{M} 3, \mathrm{~N} 3$

Proses pertumbuhan telur menjadi kecebong dengan visual di dalam air sungai

Durasi $=13$ detik

Timeline $=01: 37-01: 50$ Audio $=\mathrm{M} 2, \mathrm{~N} 2$

Proses perkembangan tubuh pada kecebong dengan visual di dalam air sungai dan kecebong bergerak berenang

Durasi $=26$ detik

Timeline $=01: 50-02: 16$ Audio = M2, N2

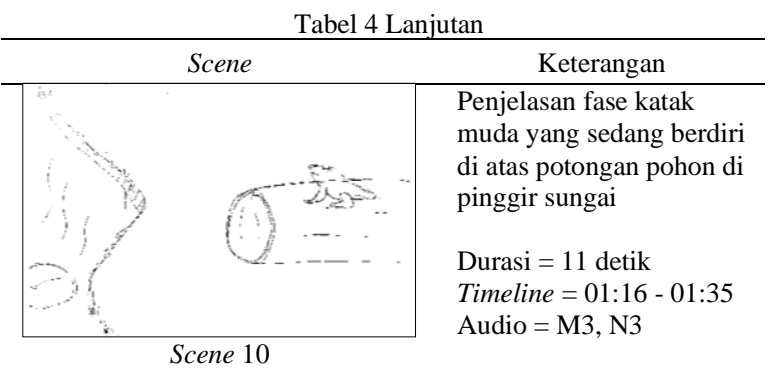




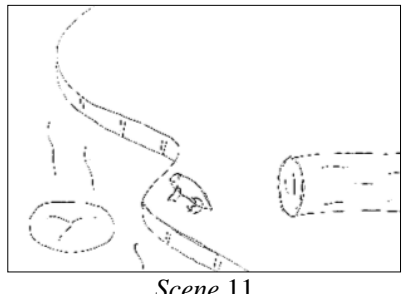

Katak muda mulai aktivitas di pinggir

sungai

Durasi $=6$ detik Timeline $=01: 36-01: 40$ Audio $=\mathrm{M} 3, \mathrm{~N} 3$

Scene 11

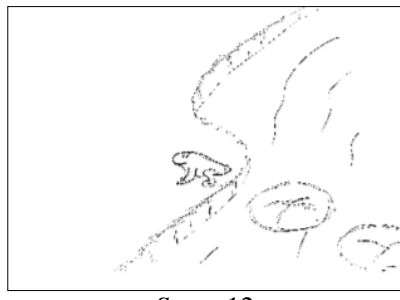

Fase katak dewasa sedang berada di pinggi sungai

Durasi $=12$ detik Timeline $=$ 03:04 - 03:16 Audio = M1, M2, M4 N5

Scene 12

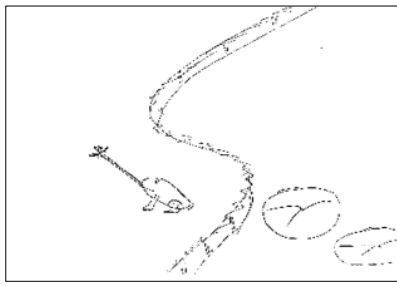

Scene 13

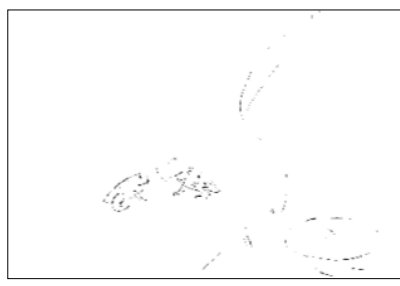

Katak bertemu dengan lawan jenis di pinggir sungai

Durasi $=7$ detik Timeline $=03: 35-03: 42$ Audio = M1, M2, M4 N6

Katak dewasa memakan serangga di pinggir sungai

Durasi $=2$ detik Timeline $=03: 17-03: 19$ Audio = M1, M2, M4 N5

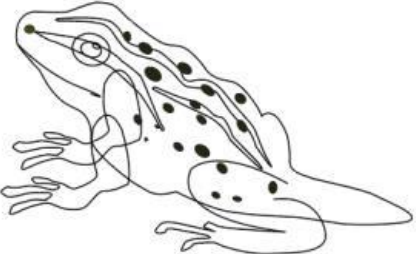

Gambar 2 membuat objek

Setelah objek selesai dibuat, proses selanjutnya adalah melakukan pewarnaan.

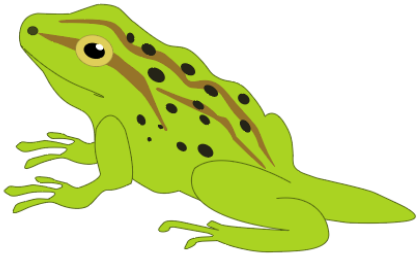

Gambar 3 pewarnaan objek karakter

Desain grafis yang dibuat digunakan sebagai bahan untuk animasi pada Adobe After Effect 2020.

\subsubsection{Sound Recording dan Sound Editing}

Proses Sound recording adalah proses perekaman audio dari narator yang membacakan teks narasi dengan menghasilkan rekaman audio berformat *.aac. Audio yang didapat melalui proses sound editing untuk menyempurnakan suara dan menyatukannya menjadi sebuah audio berformat .mp3. Proses sound editing ini menggunakan perangkat lunak Adobe Audition 2020.

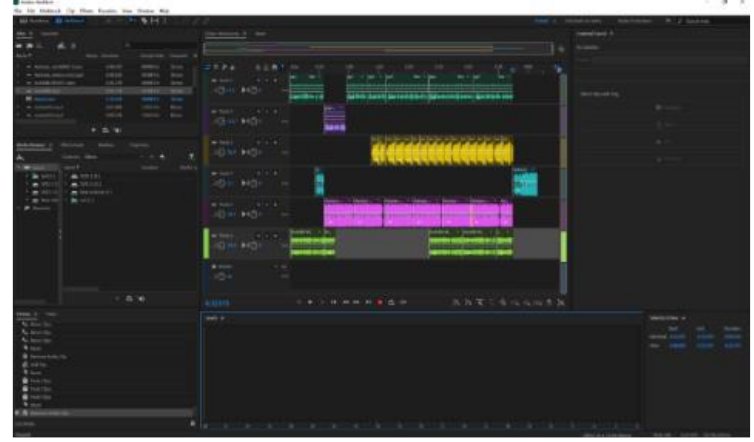

Gambar 4 Editing Sound Record Narasi

\subsubsection{Compositing}

Composing merupakan proses untuk menggabungkan kembali objek-objek yang telah dibuat menjadi satu scene. Proses ini dilakukan menggunakan software Adobe After Effect 2020.

2021. Produksi Desain Grafis menghasilkan objek karakter dan beberapa asset. Salah satu contoh objek karakter ditampilkan pada gambar 2. 


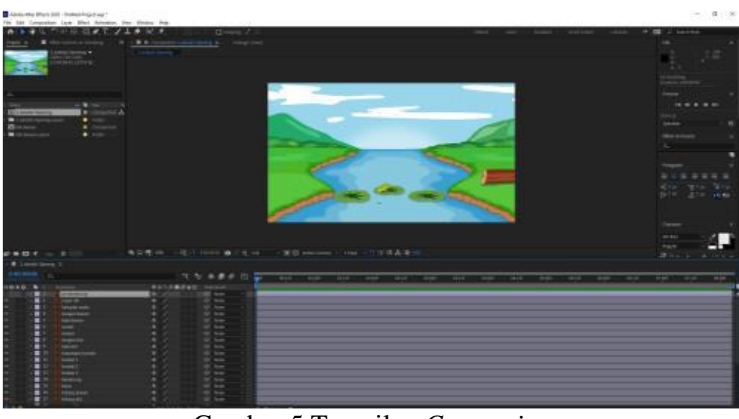

Gambar 5 Tampilan Composing

\subsubsection{Editing}

Editing dilakukan untuk mengemas dan menata semua yang telah dikerjakan sebelumnya, menyesuaikan suara dengan visual, memberi spesial efek agar menyatukan semuanya dalam satu video. Software yang digunakan pada tahap ini yaitu Adobe Premiere Pro 2020.

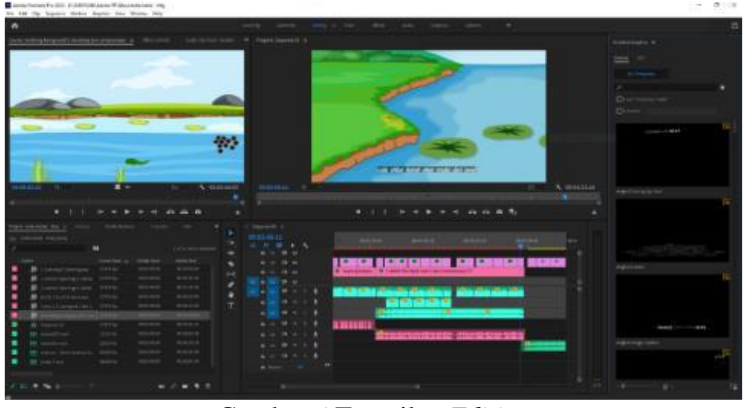

Gambar 6 Tampilan Editing

\subsubsection{Rendering}

Rendering adalah proses terakhir dari seluruh proses pembuatan video, proses rendering hasil dari proses composing dan editing di-export menjadi sebuah file video agar dapat diputar dengan software viewer. Proses rendering ini menggunakan software Adobe Premiere Pro 2020.

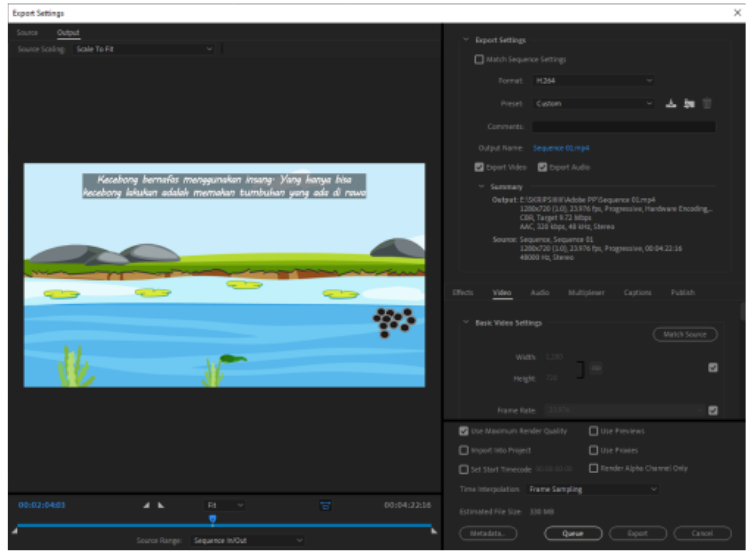

Gambar 7 Tampilan Rendering

\subsection{Tahap Pasca Produksi}

Tahap Pasca Produksi adalah tahap akhir setelah tahapan pra produksi dan produksi terlampaui. Tahap ini dilakukan pengujian dan implementasi video animasi 2D Metamorfosis Katak.

\subsubsection{Pengujian}

Mekanisme pengujian menggunakan metode kuisioner yang kemudian dihitung menggunakan metode Skala Likert. Pengujian dilakukan meliputi aspek informasi dan aspek multimedia.

Aspek informasi bertujuan untuk menilai kebutuhan informasi yang disajikan dalam video animasi $2 \mathrm{D}$ metamorfosis katak. Aspek informasi dinilai oleh 60 audience yang terdiri dari siswa dan pemirsa umum.

\begin{tabular}{clccccc}
\multicolumn{7}{c}{ Tabel 5 Hasil kuesioner pengujian siswa dan pemirsa umum } \\
\hline No & \multicolumn{1}{c}{ Pertanyaan } & SB & B & C & K & SK \\
\hline 1 & $\begin{array}{l}\text { Kualitas gambar yang } \\
\text { disajikan }\end{array}$ & 43 & 17 & 0 & 0 & 0 \\
2 & $\begin{array}{l}\text { Kualitas audio/suara } \\
\text { yang disajikan }\end{array}$ & 39 & 19 & 2 & 0 & 0 \\
3 & $\begin{array}{l}\text { Informasi materi } \\
\text { metamorfosis }\end{array}$ & 45 & 13 & 2 & 0 & 0 \\
4 & $\begin{array}{l}\text { Kejelasan } \\
\text { penyampaian } \\
\text { informasi } \\
\text { Kejelasan } \\
\text { dalam video animasi }\end{array}$ & 46 & 13 & 1 & 0 & 0 \\
\hline & 43 & 15 & 2 & 0 & 0 \\
\hline Keterangan SB: Sangat Baik, B: Baik, C: Cukup, K: Kurang
\end{tabular}

Keterangan SB: Sangat Baik, B: Baik, C: Cukup, K: Kurang, SK: Sangat Kurang

Berdasarkan hasil perhitungan menggunakan Skala Likert dari kuesioner peserta didik dan masyarakat umum, didapatkan nilai sebesar $93,9 \%$ dengan kriteria Sangat Baik.

Aspek Multimedia digunakan untuk mengukur unsur-unsur multimedia yang terdapat dalam video animasi 2D. Aspek Multimedia dinilai oleh 30 audience yang terdiri dari para praktisi multimedia.

Tabel 6 Hasil kuesioner pengujian praktisi multimedia

\begin{tabular}{|c|c|c|c|c|c|c|}
\hline No & Pertanyaan & SB & B & $\mathrm{C}$ & K & SK \\
\hline 1 & $\begin{array}{ll}\text { Penerapan } & \text { teknik } \\
\text { motion graphic } & \text { dalam } \\
\text { video } & \end{array}$ & 12 & 16 & 2 & 0 & 0 \\
\hline 2 & $\begin{array}{l}\text { Pemilihan warna } \\
\text { setiap scene }\end{array}$ & 17 & 9 & 4 & 0 & 0 \\
\hline 3 & $\begin{array}{l}\text { Kualitas audio dan } \\
\text { dubbing }\end{array}$ & 12 & 15 & 3 & 0 & 0 \\
\hline 4 & $\begin{array}{l}\text { Ilustrasi animasi dari } \\
\text { setiap objek yang } \\
\text { ditampilkan }\end{array}$ & 17 & 12 & 1 & 0 & 0 \\
\hline 5 & $\begin{array}{l}\text { Implementasi dan } \\
\text { kesesuaian storyboard }\end{array}$ & 19 & 7 & 4 & 0 & 0 \\
\hline 6 & $\begin{array}{ll}\text { Kesesuaian animasi } \\
\text { dengan audio }\end{array}$ & 19 & 10 & 1 & 0 & 0 \\
\hline 7 & $\begin{array}{l}\text { Penyampaian isi } \\
\text { materi pada animasi }\end{array}$ & 21 & 6 & 3 & 0 & 0 \\
\hline
\end{tabular}

Keterangan SB: Sangat Baik, B: Baik, C: Cukup, K: Kurang, SK: Sangat Kurang

Berdasarkan hasil perhitungan menggunakan Skala Likert dari kuesioner praktisi, multimedia didapatkan nilai sebesar $88,82 \%$ dengan kriteria Sangat Baik.

\subsubsection{Implemantasi}

Video animasi 2D metamorfosis katak dengan teknik motion graphic telah ditayangkan pada media sosial youtube dengan di kanal Titaj Setyo Wibowo. Video diunggah pada platform youtube mulai 
tanggal 13 Agustus 2021 sampai dengan 23 Agustus 2021 sudah ditonton sebanyak 60 orang.

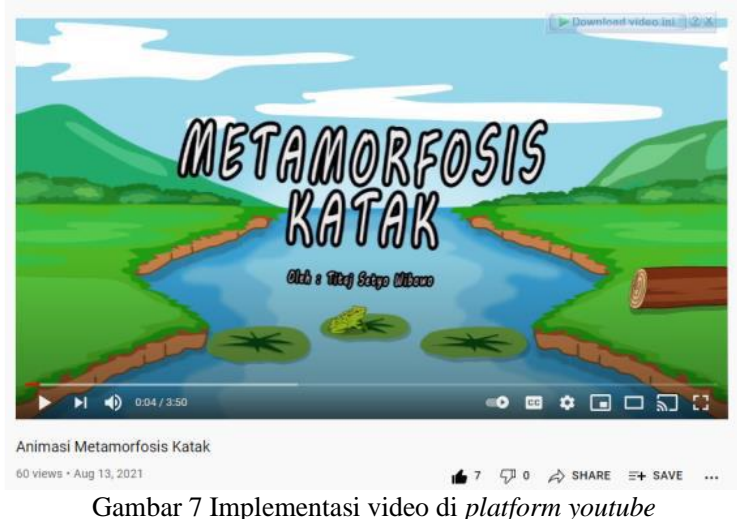

\section{Kesimpulan}

Berdasarkan penjelasan dan uraian di atas maka dapat diambil kesimpulan, sebagai berikut:

1. Penelitian ini menghasilkan sebuah video animasi 2D dengan judul Metamorfosis Katak yang berdurasi 03.50 menit dengan format .mp4 dan berukuran HD 1280x720 pixel.

2. Video animasi 2D metamorfosis katak ini dapat membantu mempermudah siswa dalam memahami proses metamorfosis pada katak karena disajikan secara visual dan informasi yang detail dan jelas.

3. Pembuatan video ini melalui tahap pra produksi yang meliputi pengumpulan data dan analisis, pembuatan tema dan konsep, serta pembuatan narasi dan storyboard. Tahap produksi meliputi pembuatan objek grafis, perekaman audio, composing, editing dan rendering. Tahap pasca produksi meliputi pengujian dan implementasi video animasi 2D metamorfosis katak.

4. Video animasi 2D metamorfosis katak diuji menggunakan metode Skala Likert. Hasil pengujian pada aspek informasi sebesar 93,9\% dengan kriteria Sangat Baik dan pengujian pada aspek multimedia sebesar $88,82 \%$ dengan kriteria Sangat Baik.

5. Implemtasi dan distribusi Video animasi Metamorfosis Katak diunggah pada platform Youtube di kanal Titaj Setyo Wibowo. Hasil penanyangan video tersebut pada tanggal 13 Agustus 2021 sampai dengan 23 Agustus 2021 sudah ditonton sebanyak 60 orang.

\section{Daftar Pustaka}

[1] Haryanto. 2007. Sains untuk Kelas 4. Jakarta: Erlangga.

[2] Sugiyono, 2011. Metode Penelitian Kualitatif, Kuantitatif dan R\&D, Bandung: Alfabeta.

[3] Callagher,R and A.M. Paldy. 2007. Exploring Motion Graphics. Californ Park,NY: Thompson Delmar Learning.

[4] Achmad Sidik. 2017. Pembuatan Video Motion Graphic Data Penerimaan Mahasiswa Baru
Universitas Negeri Jakarta Tahun 2017. Jakarta: Universitas Negeri Jakarta.

[5] Oktaviana Puspitasari. 2019. Pengembangan Media Pembelajaran Interaktif Mata Pelajaran Bahasa Jawa Untuk Pengenalan Nama Anak Binatang Kelas 2 Di SD N Plumbungan 4 Surakarta. Surakarta: Universitas Surakarta.

[6] Fujianto, R, Z \& Antoni, C. 2020. Produksi dan Efektivitas Motion Graphic Sebagai Media Promosi Zetizen Batam Pos. Batam: Politeknik Negeri Batam. 